ISSN 2525-4804

\title{
SUBSTÂNCIAS HÚMICAS NO TRATAMENTO DE SEMENTES DE ARROZ ALTERAM O VIGOR E MORFOFISIOLOGIA DAS PLÂNTULAS
}

\author{
Joao Henrique Silva da Luz ${ }^{1}$-2, Laila Sirino De Araujo ${ }^{2}$, Indira Rayane Pires Cardeal ${ }^{2}$, Hanrara Pires de \\ Oliveira $^{1-2}$, Bruno Henrique Di Napoli Nunes ${ }^{2}$, Heloisa Donizete da Silva ${ }^{3}$, Evandro Alves Ribeiro ${ }^{3}$
}

\section{RESUMO:}

O uso de substâncias húmicas pode induzir respostas fisiológicas que aumentam a produção das culturas agrícolas. Porém, poucos estudos abordam seu uso no tratamento de sementes, e quando associado a cultura do arroz são quase inexistentes. Desta forma, o objetivo foi avaliar as respostas da aplicação de substâncias húmicas no tratamento de sementes sobre no o vigor, morfologia, acúmulo de biomassa e na fisiologia das plântulas de arroz, cultivar IRGA 431. O estudo foi realizado com quatro doses de substâncias húmicas $\left(0,50,100\right.$ e $150 \mathrm{~mL} 100 \mathrm{~kg}^{-1}$ de sementes) aplicadas no tratamento de sementes, dispostas em delineamento inteiramente casualizado, com quatro repetições e 40 sementes cada. As substâncias húmicas foram extraídas de composto ruminal com $\mathrm{KOH}$ e aplicadas diretamente nas sementes. A cultura foi cultivada até o estádio V3 e variáveis sobre germinação, morfologia, biomassa e fisiologia mensurados e avaliados por análise de variância $(\mathrm{p} \leq 0,05)$ com os modelos ajustados por regressões polinomiais. Houve resposta positiva, principalmente, sobre o índice de velocidade de emergência, volume de raiz, biomassa da parte aérea e taxa de assimilação de $\mathrm{CO}_{2}$ na ordem de 10,13, 53 e 73\%, respectivamente. Esses resultados evidenciam que as substâncias húmicas associadas ao tratamento de sementes potencializam o desenvolvimento inicial da cultura do arroz.

Palavras-chave: Bioestimulantes, Oryza sativa, plântulas.

\section{HUMIC SUBSTANCES IN THE TREATMENT OF RICE SEEDS ALTER THE SEEDLING VIGOR AND MORPHOPHYSIOLOGY}

\begin{abstract}
:
The use of humic substances can induce physiological responses that increase the production of agricultural crops. However, few studies address its use in seed treatment, and when associated with rice cultivation are almost non-existent. Thus, the objective was to evaluate the responses of the application of humic substances in the treatment of seeds on vigor, morphology, biomass accumulation and in the physiology of rice seedlings, cultivate IRGA 431. The study was conducted with four doses of humic substances $(0,50$,

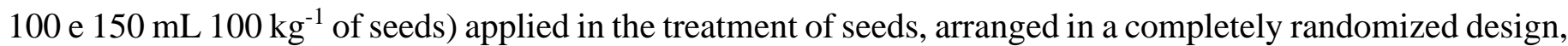
with four replications and 40 seeds each. The humic substances were extracted from ruminal compound with
\end{abstract}

\footnotetext{
${ }^{1}$ Universidade de São Paulo, Programa de Pós-graduação em Solos e Nutrição de Plantas, Piracicaba - SP, *E-mail: jhluz@usp.br;

${ }^{2}$ Universidade Federal do Tocantins, Colegiado de Agronomia, Gurupi - TO;

${ }^{3}$ Universidade Federal do Tocantins, Programa de Pós-graduação em Produção Vegetal, Gurupi - TO.
} 
ISSN 2525-4804

$\mathrm{KOH}$ and applied directly to the seeds. The crop was cultivated up to stage V3 and variables on germination, morphology, biomass and physiology measured and evaluated by analysis of variance $(p \leq 0.05)$ with models adjusted by polynomian regressions. There was a positive response, mainly, about the emergence speed index, root volume, shoot biomass and $\mathrm{CO}_{2}$ assimilation rate in the order of 10, 13, 53 and $73 \%$, respectively. These results show that humic substances associated with seed treatment potentiate the initial development of rice culture.

Key Words: Biostimulants, Oryza sativa, seedlings. 


\section{INTRODUÇÃO}

O arroz (Oryza sativa L.) é um dos cereais mais produzidos e consumidos no mundo, e por compor a dieta de dois terços da população mundial é tido como um dos principais alimentos humano (FAO, 2020). A produção mundial estimada do grão é mais de 475 milhões de toneladas, destas, 8,3 milhões são produzidas no Brasil (USDA, 2020).

Para atender à demanda crescente deste alimento, Seck et al. (2012) estimam que os produtores de arroz precisam aumentar a produção anual em 1,2-1,5\% até 2022, mesmo sem expandir a área de cultivo. Uma potencial estratégia para alcançar essa meta é o uso de bioestimulantes de plantas (BPs), tanto no tratamento das sementes como nos estádios mais avançados das culturas (Jindo et al., 2020). Os BPs podem aumentar o crescimento e desenvolvimento das plantas, além de atenuar os efeitos dos estresses abióticos, o que resulta em maior potencial de aumento da produtividade (Cataneo et al., 2010; Grohs et al., 2012).

As substâncias húmicas ( $\mathrm{SHs}$ ) podem ser usadas nas plantas em baixas concentrações para aumentar o crescimento, melhorar a absorção de nutrientes e a produtividade agrícola, constituindo assim uma categoria popular de bioestimulantes vegetal (Du Jardin, 2015; Yakhin et al., 2017). Esses efeitos são atribuídos a capacidade das SHs atuarem como substâncias bioativas nos metabolismos primário e/ou secundário, o que desencadeia ampla gama de respostas bioquímicas, fisiológicas e moleculares (Canellas et al., 2020).

O uso de SHs em culturas agrícolas é relatado desde 1980 (Jindo et al., 2020) e o modo de aplicação mais frequente é via foliar, que na cultura do arroz não pode ser realizada após o florescimento por causar a descoloração das espiguetas. Além disso, em condição de deficiência de nutrientes respostas positivas da aplicação foliar são pouco prováveis, mostrando- se menos consistentes do que aquelas observadas quando aplicada na raiz, onde as SHs é exposta a uma condição mais estável (Jindo et al., 2020).

Dessa forma, poucos estudos relacionam o uso de SHs na cultura do arroz e seus possíveis efeitos sobre os primeiros estádios fenológicos da cultura. Com isso, nossa hipótese é que a aplicação de SHs no tratamento de sementes pode promover ganhos significativos sobre o crescimento e desenvolvimento de plântulas de arroz. Por isso, o objetivo foi avaliar o efeito do uso de substâncias húmicas no tratamento de sementes sobre o vigor, morfologia, acúmulo de biomassa e na fisiologia das plântulas de arroz, cultivar IRGA 431.

\section{MATERIAL E MÉTODOS}

O estudo foi conduzido em casa de vegetação na Universidade Federal do Tocantins, na cidade de Gurupi, Tocantins (11 ${ }^{\circ} 43^{\prime} 45^{\prime}$ ' S, 49 $04^{\prime} 07^{\prime}$ ' W), a $287 \mathrm{~m}$ de altitude. O clima regional é do tipo B1wA'a' úmido com moderada deficiência hídrica. A temperatura média anual é de $29,5^{\circ} \mathrm{C}$ com precipitação média anual de $1600 \mathrm{~mm}$ (Alvares et al., 2013).

$\mathrm{O}$ experimento foi conduzido em delineamento inteiramente casualizado, com quatro doses de substâncias húmicas (SHs) $(0$, 50, 100 e $150 \mathrm{~mL} 100 \mathrm{~kg}^{-1}$ de sementes) aplicadas no tratamento de sementes de arroz, com quatro repetições de 40 sementes cada. As doses foram definidas com bases em ensaios de pré-testes (dados não publicados).

As SHs utilizadas foram extraídas a partir de compostagem de resíduo ruminal bovino com $\mathrm{KOH}$ a $0,1 \mathrm{~mol} \mathrm{~L}^{-1}$ como extrator, conforme metodologia proposta por Mendonça \& Matos (2005). As SHs obtidas foram caracterizadas com $27 \mathrm{~g} \mathrm{~kg}^{-1}$ de carbono orgânico e $10 \mathrm{~g} \mathrm{~kg}^{-1} \mathrm{de}$ nitrogênio total.

As sementes de arroz, cultivar IRGA 431 foram adquiridas comercialmente (certificadas) da empresa Uniggel Sementes ${ }^{\odot}$. A aplicação dos 
tratamentos foi realizada em lotes de $1 \mathrm{~g}$ de sementes ( 55 un) separadas em sacos plásticos para cada repetição. Em seguida, aplicou-se 100 $\mu \mathrm{L}$ (por repetição) de uma solução preparada previamente em água destilada com concentrações de SH correspondente a cada dose. Esse volume foi utilizado por não encharcar o lote de sementes. Após serem homogeneizados manualmente, os sacos plásticos foram abertos e permaneceram em bancada por $16 \mathrm{~h}$ a $25^{\circ} \mathrm{C}$ para leve secagem das sementes.

As sementes foram semeadas em tubetes contendo substrato composto por mistura de areia lavada, solo (ambos peneirados em malha de $2 \mathrm{~mm}$ ) e substrato comercial (Terra Nova ${ }^{\circledR}$ ) na proporção 2:2:0,5. Durante a homogeneização do substrato foi acrescentado $10 \mathrm{~g}$ do formulado 5-

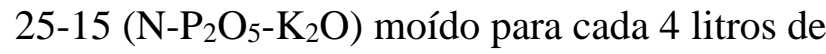
substrato. Após o semeio, uma semente por tubete, o substrato foi irrigado três vezes ao dia para manter próximo a $100 \%$ da capacidade de campo (ou seja, o volume de água aplicado foi o suficiente para não promover lixiviação).

\section{Variáveis avaliadas}

As plântulas emergidas (plântulas normais com folhas primarias completamente expandidas) foram contadas diariamente no mesmo horário, do $5^{\circ}$ ao $15^{\circ}$ dias após a semeadura (DAS), conforme normas preconizadas pela Regra Para Análises de Sementes (Brasil, 2009). A porcentagem de germinação foi determinada aos 15 DAS, e o índice de velocidade de emergência (IVE) calculado conforme fórmula de Maguire (1962).

Aos 20 DAS, as trocas gasosas foram medidas em folhas completamente expandidas, das 8 às 11 h30 da manhã em dia ensolarado, com equipamento de sistema aberto de fotossíntese com analisador de $\mathrm{CO}_{2}$ e vapor d'água por radiação infravermelha (Infra Red Gas Analyser - IRGA, modelo LCiSD, da ADC System, UK). Foram determinados a taxa de assimilação de
$\mathrm{CO}_{2}\left(A, \mu \mathrm{mol}\right.$ de $\left.\mathrm{CO}_{2} \mathrm{~m}^{-2} \mathrm{~s}^{-1}\right)$, a eficiência do uso da água (EUA, $\mu$ mol $\mathrm{CO}_{2}$ mmol $\mathrm{H}_{2} \mathrm{O}^{-1}$ ) e a eficiência instantânea de carboxilação da enzima ribulose 1, 5-difosfato carboxilase (Rubisco) (EIC, $\mu \mathrm{mol} \mathrm{CO} \mathrm{Cm}^{-2} \mathrm{~s}^{-1}$ (mol ar) ${ }^{-1}$ ) (Zhang et al., 2001). Com o aparelho clorofiLOG determinouse, em 10 folhas completamente expandidas para cada repetição, o índice de clorofila Falker (ICF) (FALKER, 2008).

Altura das plântulas foi mensurada com auxílio de uma régua graduada em centímetros. Em seguida, folhas e caules das plântulas foram destacados das raízes. As raízes foram lavadas em água corrente para completa remoção do substrato. Após secagem rápida com papel filtro para não perder turgescência, determinou-se o volume de raiz (VR) pelo método da proveta. Este método consiste na variação do volume d'água na proveta após adição da biomassa fresca das raízes.

Ambas as partes morfológicas (parte aérea e raiz) foram acondicionadas separadamente em sacos de papel para serem secas em estufa com circulação forçada de ar a $65^{\circ} \mathrm{C}$ por 72 horas, ou até obterem peso constante. Após pesagem em balança analítica $(0,0001 \mathrm{~g})$ obteve-se a massa seca da parte aérea (MSPA, g) e da raiz (MSR, g), a relação entre a massa seca da parte aérea e raiz (RPAR, $\mathrm{g} \mathrm{g}^{-1}$ ) e a massa seca total (MSR+MSPA) (MST, g).

\section{Análise estatística}

Os resultados foram analisados por análise de variância (ANOVA, $\mathrm{p} \leq 0,05) \quad \mathrm{e}$, posteriormente a análise de regressão. Os modelos foram ajustados conforme o nível de significância dos coeficientes de determinação, e os limites de $95 \%$ de confiança das equações foram expostos nos gráficos. Todas as análises e gráficos foram realizadas no programa $\mathrm{R}^{\circledR}$ versão 4.0.2 (TEAM, 2020).

\section{RESULTADOS E DISCUSSÃO}


O uso de substâncias húmicas (SHs) no tratamento de sementes (TS) de arroz da cultivar IRGA 431 promoveu alterações significativas no vigor das sementes, no acúmulo de biomassa e na fisiologia do desenvolvimento inicial das plântulas (até 20 DAS, estádio V3). O índice de velocidade de emergência (IVE) apresentou resposta quadrática $(\mathrm{p}=0,02, \mathrm{CV}=4,7 \%)$, com melhor resposta na dose de $75 \mathrm{~mL} 100 \mathrm{~kg}^{-1}$ de semente que apresentou máximo IVE estimado $(29,52)$. Acréscimo de $10,1 \%$ em relação ao controle com 26,76. Doses acima de $75 \mathrm{~mL} 100$ $\mathrm{kg}^{-1}$ de semente provocaram redução do IVE na ordem de $-0,1 \%$ para cada $\mathrm{mL}$ de SHs aplicado (Fig. 1-A).
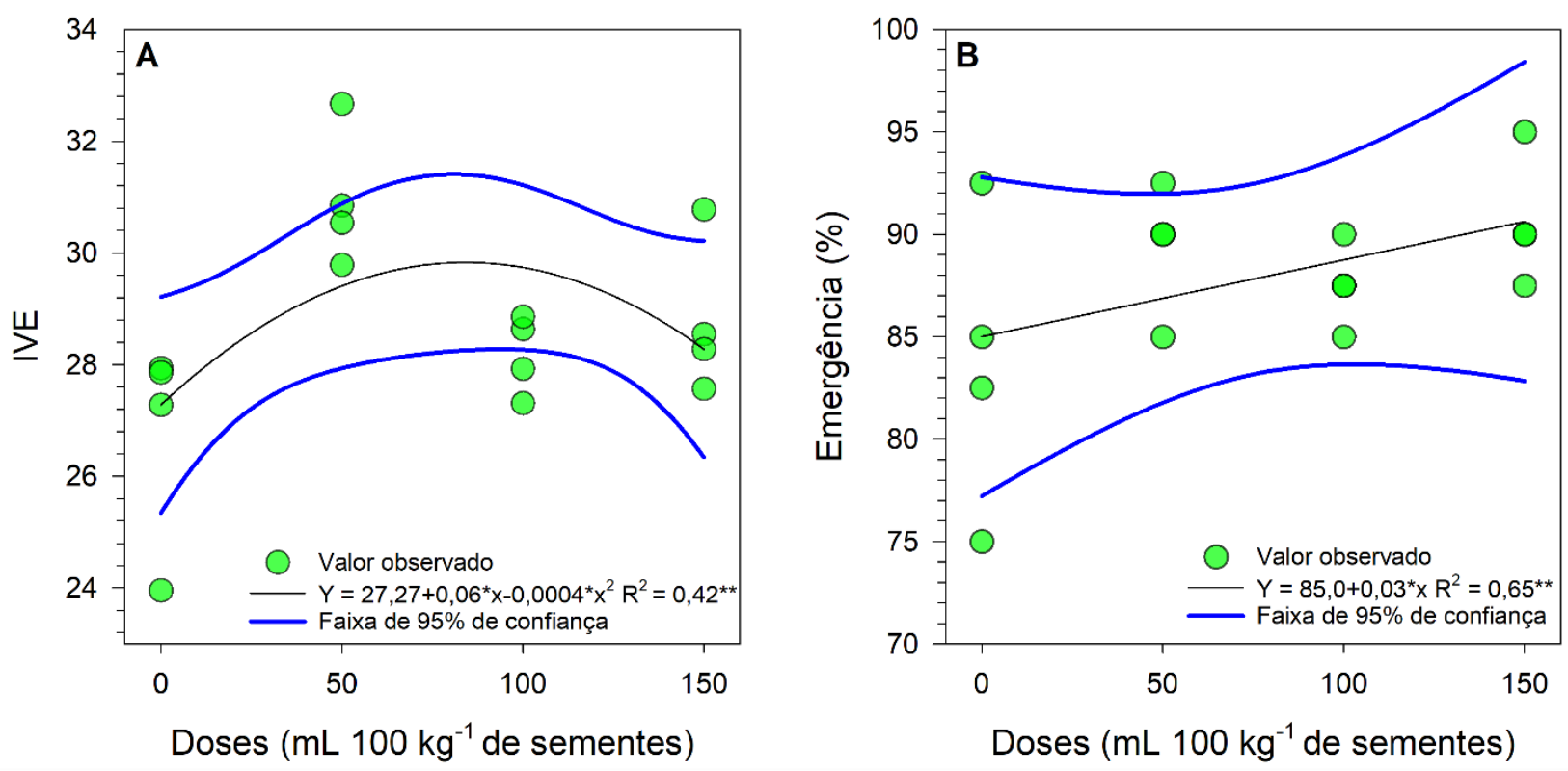

Figura 1. Índice de velocidade de emergência (IVE) (A) e porcentagem de emergência (B) de plântulas de arroz sob uso de substâncias húmicas no tratamento de sementes.

Resultados semelhantes foram descritos por Mota et al., (2015), evidenciando o efeito das SHs no IVE, com maior germinação diária na concentração de $0,25 \%$ das sementes de Myracrodruon urundeuva. Nota-se que a porcentagem de germinação teve resposta linear aos tratamentos (Fig. 1-B). Contudo, Camargo et al. (2001) mostrou resultados contrários, verificando que doses superiores a $100 \mathrm{~mL}$ gera efeito negativo, o que evidencia que os bioestimulantes quando mal recomendado pode gerar fitotoxidez, o que pode limita o vigor das plântulas na germinação, bem como a geração de consequências sobre para o desenvolvimento da cultura.
Porcentagem de sementes emergidas aos 15 DAS apresentou resposta linear $(p=0,045)$, com $89,5 \%$ na dose de $150 \mathrm{~mL} 100 \mathrm{~kg}^{-1}$ de sementes, com percentual de $6,8 \%$ superior ao controle $(83,7 \%, \pm 7,2 \%)$ (Fig. 1-B). Vale ressaltar que a determinação desta variável ocorreu, conforme Brasil (2009), para a cultura do arroz e que aos 20 DAS todos os tratamentos atingiram $100 \%$ de emergência. Em condições de campo, Elli et al. (2016) verificaram resposta positivas na germinação de quatro cultivares de arroz com uso bioestimulante comercial (Stimulate ${ }^{\circledR}$ ) a base de SHs no TS. A melhor resposta dose descrita foi 3 $\mathrm{mL} \mathrm{kg}^{-1}$ de sementes, valor duas vezes maior que os resultados encontrados neste trabalho. Esta 
diferença pode estar associada a baixa concentração de SHs no produto comercial.

A resposta da altura $(\mathrm{p}=0,01)$ e massa seca da parte aérea (MSPA) $(\mathrm{p}=0,004)$ das plântulas de arroz foram ajustadas curvas quadráticas, cujos coeficientes de determinação foram $93 \%$ (p

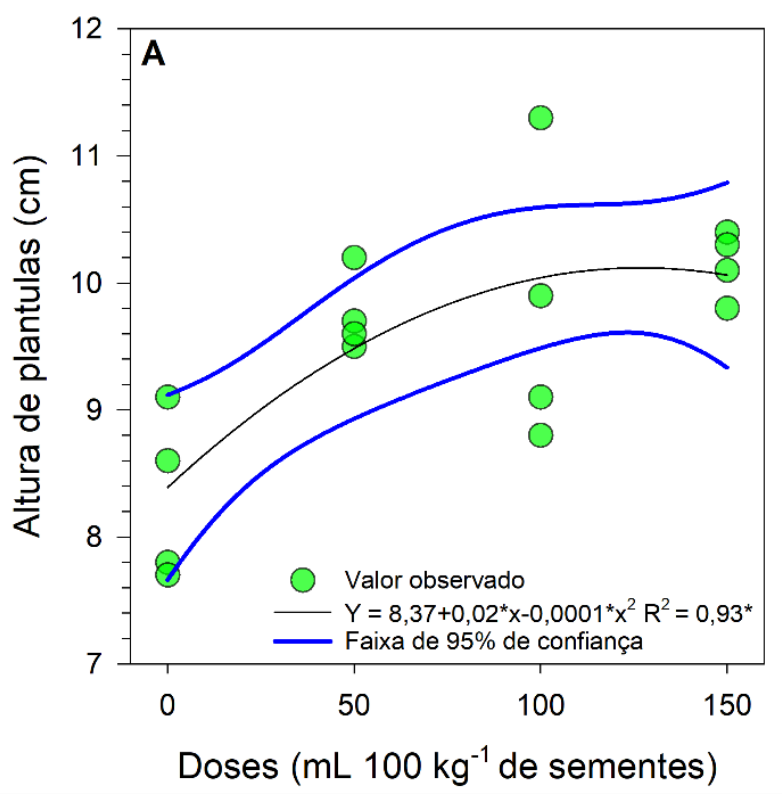

Figura 2. Altura (A) e massa seca da parte aérea (MSPA) (B) de plântulas de arroz sob uso de substâncias húmicas no tratamento de sementes.

Para MSPA, houve resposta positiva $(\mathrm{p}=$ $0,004)$ até a dose $100 \mathrm{~mL} 100 \mathrm{~kg}^{-1}$ onde ocorreu o máximo acúmulo de matéria seca $(13,83 \mathrm{~g}, \mathrm{p}=$ 0,005), com um acréscimo de 53,5\% em relação ao controle de (8,83 g) de MSPA (Fig. 2-B). Após esta dose a redução ocorreu $-0,2 \%$ para cada $\mathrm{mL}$ de SHs aplicada no TS. Porém, mesmo na máxima dose $\left(150 \mathrm{~mL} 100 \mathrm{~kg}^{-1}\right)$ as plântulas apresentaram aumento na MSPA de 39,4\% em relação ao controle, o que demonstra baixa toxidez e alto potencial de uso SHs para bioestimulação do acúmulo de biomassa nos estádios iniciais da cultura do arroz.

A massa seca da raiz (MSR) foi alterada ( $p$ $=0,003$ ) conforme o aumento das doses de SHs, onde houve estímulos benéficos até $50 \mathrm{~mL} 100$ $\mathrm{kg}^{-1}$ de sementes $(\mathrm{p}=0,049)$, com incremento de $1,04 \mathrm{~g}$ ou 13,3\% de MSR em relação ao controle (Fig. 3-A). Esse modelo de regressão ajustada é característico da ação de hormônios vegetais e
$=0,003)$ e $90 \%(\mathrm{p}=0,005)$, respectivamente (Fig. 2-A). Altura máxima ocorreu na dose de $100 \mathrm{~mL} 100 \mathrm{~kg}^{-1}$ de sementes, com 9,37 cm, um acréscimo de $1,08 \mathrm{~cm}$ por plântula ou $12,9 \%$ quando comparado com o controle $(8,28 \mathrm{~cm})$.

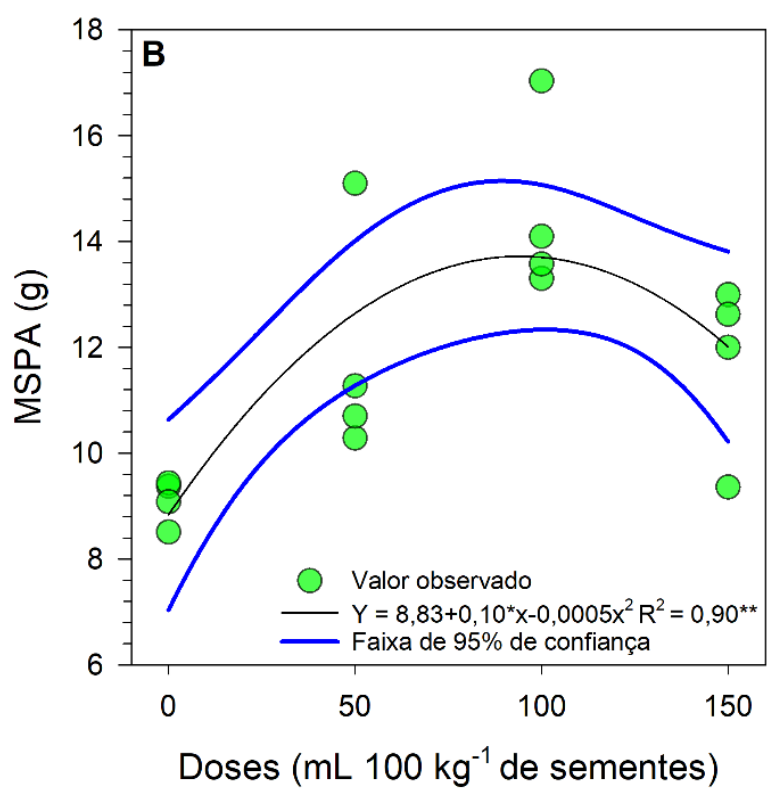

também do uso de substâncias húmicas $(\mathrm{SH})$ sobre o desenvolvimento de plantas (García et al., 2019).

Para o volume de raiz o acréscimo foi estimado em $0,384 \mathrm{~mL}$ ou $16,4 \%\left(\mathrm{p}=0,04, \mathrm{R}^{2}=\right.$ $0,66)$ na dose de $80 \mathrm{~mL} 100 \mathrm{~kg}^{-1}$ de sementes (Fig. 3-B). Esta resposta é bem relatada na literatura como uma influência típica das SHs sobre a emissão de pelos radiculares e raízes laterais finas, o que resulta no aumento da área superficial e/ou comprimento do sistema radicular (Quaggiotti et al., 2004).

Alterações no comportamento de raízes através do efeito bioestimulantes das SHs já foram apresentadas em diversas espécies como milho (Anjum et al., 2011), soja (Chen et al. 2004) e trigo (Tahir et al., 2011). A dose correta de SHs promove o desenvolvimento de raízes devido ao efeito mimetizador de auxinas, que ativam sítios enzimáticos indutores da 
multiplicação dos sítios mitóticos e síntese de enzimas $\mathrm{H}^{+}$-ATPases que transportam íons entre a membrana plasmática e o citosol celular (Eyheraguibel et al., 2008; Shah et al., 2018). Além disso, a resposta no sistema radicular também pode ser associada ao favorecimento das SHs na interação plantas-microrganismos que realizam processos benéficos às plantas (exemplo: produção de auxinas, solubilização e absorção de nutrientes) (Jindo et al., 2020).
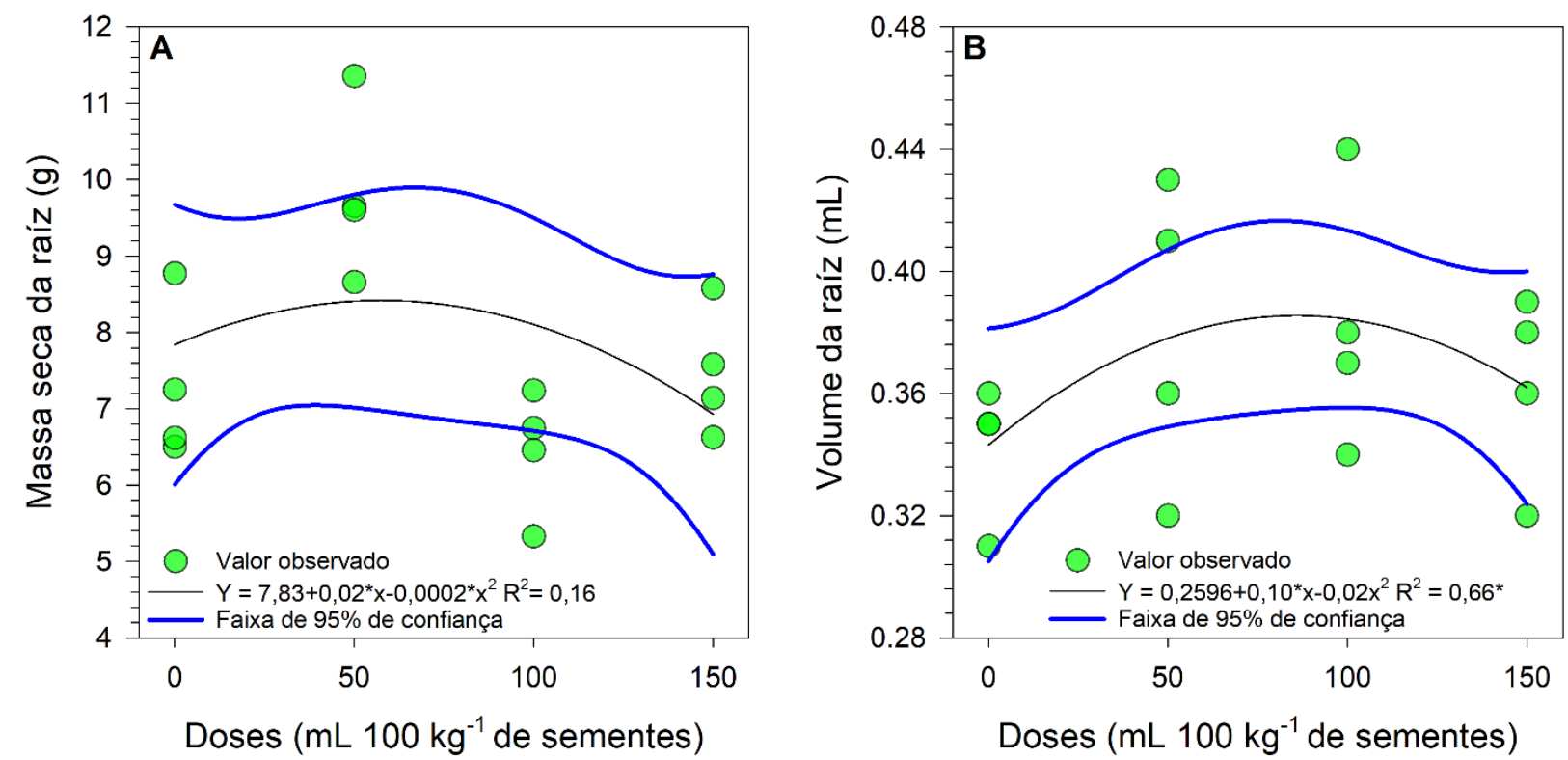

Figura 3. Massa seca da raiz (MSR) (A) e volume de raiz (B) de plântulas de arroz sob uso de substâncias húmicas no tratamento de sementes.

A produção de massa seca total (MST) das plântulas de arroz foi influenciada pelas doses de SHs $(p=0,002)$ (Fig. 4-A). Com ajuste quadrático ( $\mathrm{p}=0,0009)$, a máxima MST foi 21,81 g na dose estimada de $85,71 \mathrm{~mL} \mathrm{~kg}^{-1}$, $30,8 \%$ superior em relação ao controle $(16,67 \mathrm{~g})$. Parte dos impactos bioestimulantes das substâncias húmicas na cultura do arroz tem sido correlacionada à sua atuação análoga aos hormônios vegetais da classe das auxinas, isto é, podem proporcionar o crescimento vegetal em concentrações pequenas (Silva et al., 2020).

Na cultura do tomilho, Noroozisharaf \& Kaviani (2018) verificaram resultados semelhantes com SHs aplicados em pó no solo na dose de $75 \mathrm{~g} \mathrm{~m}^{-2}$, com aumento na produção da cultura e na qualidade do óleo essencial, o que indica efeitos significativos sobre o metabolismo secundário. Neste mesmo estudo, a aplicação de
$100 \mathrm{~g} \mathrm{~m}^{-2}$ de SHs melhorou o teor dos nutrientes foliares em razão da modulação positiva do transporte de nutrientes por meio da quelação e pela estimulação da atividade microbiana devida interação com SHs. Dessa forma, justifica o aumento da MST devido os aumentos registrados nas variáveis do sistema radicular (Fig. 3-A-B). Segundo García et al. (2019), o uso de SHs estimula a exsudação radicular que podem modular a estrutura da comunidade microbiana da rizosfera, a qual resulta no aumento do desenvolvimento e acúmulo de biomassa das plantas.

A relação parte aérea/raiz (RPAR), mostra em qual estrutura morfológica as plântulas estavam acumulando mais carbono, apresentou efeito significativo ( $p=0,001$ ) (Fig. 4-B). O ajuste quadrático com maior resposta foi na dose de $50 \mathrm{~mL} 100 \mathrm{~kg}^{-1}$, com relação de 1,37, e 
superioridade de 22,32\% em relação ao controle $(1,12)$, na ausência de substâncias húmicas.

A taxa de assimilação de $\mathrm{CO}_{2}(A)$, que é uma medida indireta da atividade fotossintética bruta das plântulas de arroz, foi influenciada linearmente $\left(\mathrm{p}=0,002, \mathrm{R}^{2}=0,84\right)$, com máxima resposta $5,68 \mu \mathrm{mol}$ de $\mathrm{CO}_{2} \mathrm{~m}^{-2} \mathrm{~s}^{-1}$ em $150 \mathrm{~mL}$ $100 \mathrm{~kg}^{-1}(\mathrm{p}=0,0005,73,1 \%$ em relação ao controle) (Fig. 5-A). Este aumento substancial justifica partes dos ganhos sobre MSPA (Fig. 2B), MSR (Fig. 3-A) e MST (Fig. 4-A), visto que o acúmulo de carbono pelas plantas (fotossíntese líquida) é resultado da assimilação de $\mathrm{CO}_{2}$ máxima (fotossíntese bruta) menos o consumo de carbono orgânico da fotorrespiração (Taiz et al., 2017).

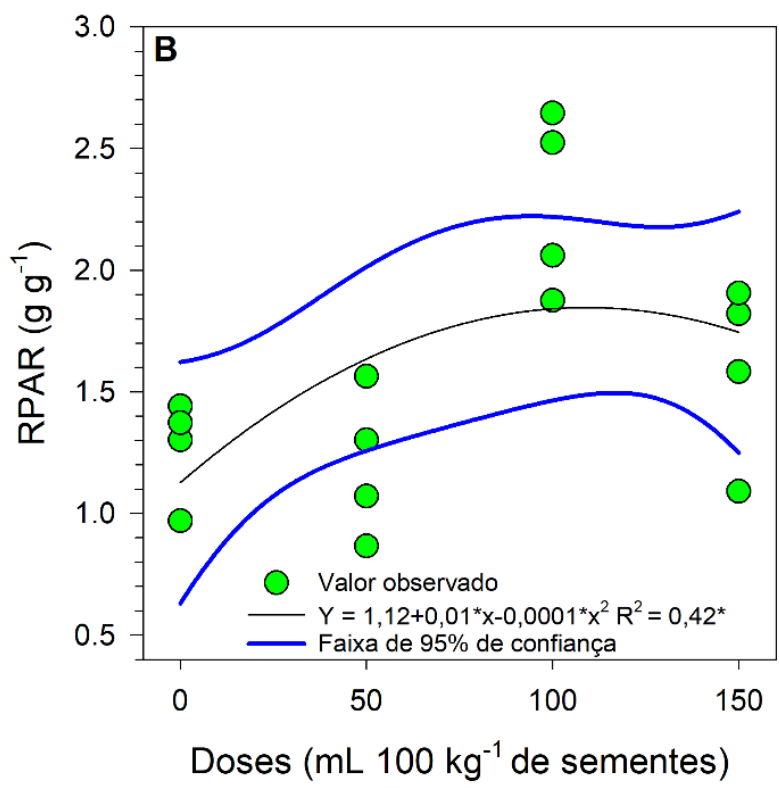

Figura 4. Massa seca total (A) e relação da parte aérea e raiz (RPAR) (B) de plântulas de arroz sob uso de substâncias húmicas no tratamento de sementes.

A alta atividade fotossíntese não possui relação linear com o acúmulo de biomassa das plantas por conta do excesso da produção de subprodutos tóxicos que reduzem sua eficiência. Estes subprodutos são convertidos na fotorrespiração em componentes metabolicamente úteis, mas ao custo da energia perdida (carbono orgânico) (South et al., 2019). As SHs podem atuar justamente nesse ponto, como agente antioxidantes direto (García et al., 2019), ou na regulação de processos metabólicos (Shah et al., 2018) que mantém a homeostase das células vegetais, colaborando com aumento do potencial fisiológico e produtivo das plantas (Jindo et al., 2020).
A eficiência instantânea da carboxilação (EIC), taxa em que o $\mathrm{CO}_{2}$ atmosférico é transformado em C-orgânico, apresentou resposta semelhante a $A(\mathrm{p}=0,006)$, com aumento de $0,0001 \mu \mathrm{mol} \mathrm{CO}_{2} \mathrm{~m}^{-2} \mathrm{~s}^{-1}(\mathrm{~mol} \mathrm{ar})^{-1}$ para cada $\mathrm{mL}$ de $\mathrm{SH}$ utilizada $\left(\mathrm{p}=0,001, \mathrm{R}^{2}=\right.$ 0,84) (Fig. 5-B). O aumento da EIC está diretamente correlacionado com atividade da enzima Ribulose 1,5-bisfosfato carboxilaseoxigenase (Rubisco), enzima chave da fotossíntese, que pode representar $\sim 50 \%$ da proteína solúvel foliar (Taiz et al., 2017).

Para eficiência do uso da água (EUA) (fig. 6-A) e o índice de clorofila Falker (EIC) (Fig. 6B) não houve ajuste significativo ( $p=0,3$ e 0,19, respectivamente) que podem ser justificados pela 
alta dispersão dos resultados destas variáveis (CV $=30,8$ e 27,8\%, respectivamente). Embora não houve ajuste matemático, foi observado aumento de 45,6\% na EUA com $100 \mathrm{~mL} \mathrm{~kg}^{-1}$ quando comparado com o controle, uma diferença de $0,4 \mu \mathrm{mol} \mathrm{CO} \mathrm{CO}_{2} \mathrm{mmol} \mathrm{H}_{2} \mathrm{O}^{-1}$ entre os dois tratamentos, que podem resultar em ganhos expressivos para os próximos estádios fenológicos. Essa diferença é importante, principalmente, para os cultivos em sequeiro onde cultura tem menor disponibilidade de água para manter sua atividade fotossintética ativa e eficiência produtiva (Taiz et al., 2017).
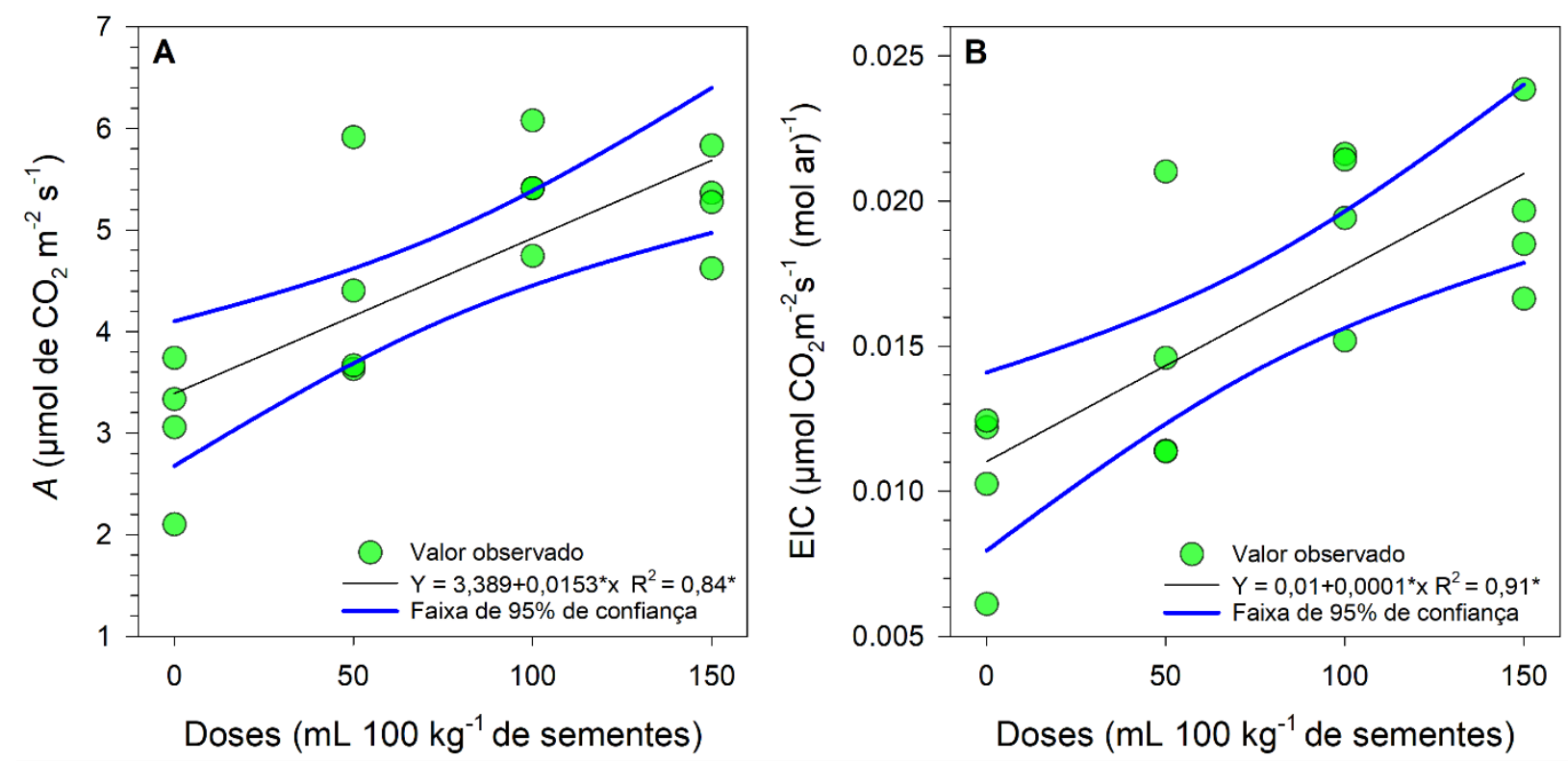

Figura 5. Assimilação de $\mathrm{CO}_{2}$ (A) (A) e eficiência instantânea da carboxilação (EIC) (B) de plântulas de arroz sob uso de substâncias húmicas no tratamento de sementes.
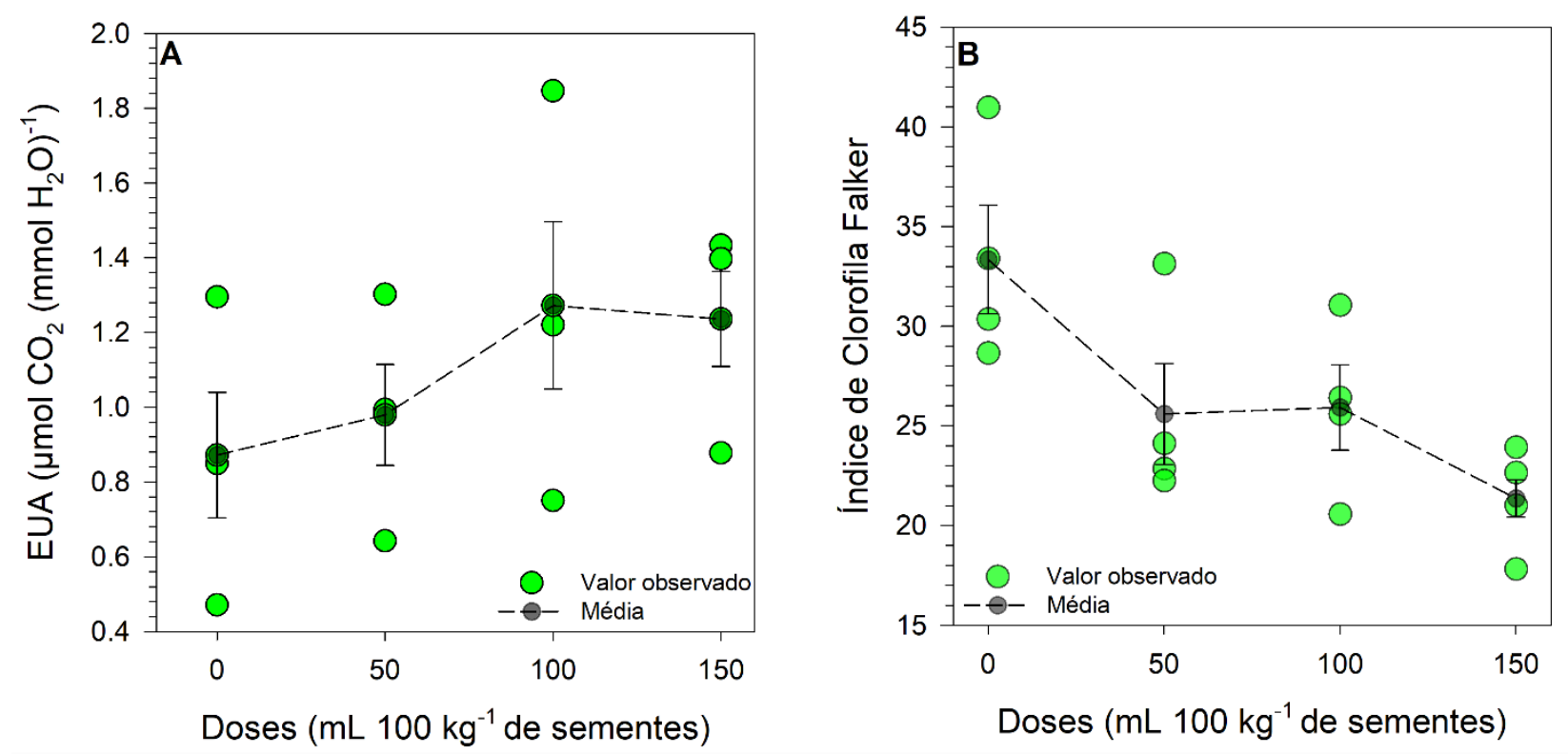

Figura 6. Eficiência do uso da água (EUA) (A) e Índice de clorofila Falker (ICF) (B) de plântulas de arroz sob uso de substâncias húmicas no tratamento de sementes. 
Estes resultados dão suporte a novas hipóteses que SHs associadas ao tratamento de sementes podem potencializar o cultivo e a produtividade da cultura do arroz devido sua capacidade de modular o crescimento e desenvolvimento dos primeiros estádios fenológicos. Dessa forma, encorajamos novos estudos que avaliem o ciclo completo da cultura, principalmente em ambientes com restrição hídrica.

\section{CONCLUSÃO}

O uso de substâncias húmicas no tratamento de sementes da cultivar de arroz IRGA 431 resulta em efeitos substanciais sobre o vigor e desenvolvimento inicial da cultura. Esta resposta inicial parece estar associada principalmente ao condicionamento fisiológico das sementes promovido pelas substâncias húmicas. Porém, novos estudos precisam ser realizados para validar se esses ganhos iniciais repercutem no aumento da produtividade da cultura.

\section{AGRADECIMENTOS}

Os autores agradecem a Universidade Federal do Tocantins e a CAPES (Coordenação de Aperfeiçoamento de Pessoal de Nível Superior) pelo apoio a JL, ER e HS.

\section{REFERÊNCIAS BIBLIOGRÁFICAS}

Alvares, C. A., Stape, J. L., Sentelhas, P. C., De Moraes Gonçalves, J. L., \& Sparovek, G. (2013). Köppen's climate classification map for Brazil. Meteorologische Zeitschrift, 22(6), 711-728. https://doi.org/10.1127/0941-2948/2013/0507

\section{Brasil. (2009). Regra para análise de sementes}

(P. e A. Ministério da Agricultura (ed.); 1st ed.). Mapa/ACS.

http://www.agricultura.gov.br/assuntos/insumos -agropecuarios/arquivos-publicacoesinsumos/2946_regras_analise_sementes.pdf
Canellas, L. P., Canellas, N. O. A., Luiz Eduardo, L. E. S., Olivares, F. L., \& Piccolo, A. (2020). Plant chemical priming by humic acids. Chemical and Biological Technologies in Agriculture, $7(1), \quad 12$. https://doi.org/10.1186/s40538-020-00178-4

Cataneo, A. C., Ferreira, L. C., Carvalho, J. C., Andréo-Souza, Y., Corniani, N., Mischan, M. M., \& Nunes, J. C. (2010). Improved germination of soybean seed treated with thiamethoxam under drought conditions. Seed Science and Technology, 38(1), 248-251. https://doi.org/10.15258/sst.2010.38.1.27

Du Jardin, P. (2015). Plant biostimulants: Definition, concept, main categories and regulation. Scientia Horticulturae, 196, 3-14. https://doi.org/10.1016/j.scienta.2015.09.021

FALKER. (2008). Manual do medidor eletrônico de teor de clorofila. http://www.falker.com.br/produto-clorofilogmedidor-clorofila.php

\section{FAO. (2020). Food and Agriculture} Organization of the United Nations. Retrieved February 6, 2021, from http://www.fao.org/home/en/

García, A. C., van Tol de Castro, T. A., Santos, L. A., Tavares, O. C. H., Castro, R. N., Berbara, R. L. L., \& García-Mina, J. M. (2019). StructureProperty-Function Relationship of Humic Substances in Modulating the Root Growth of Plants: A Review. Journal of Environmental Quality, 48(6), 1622-1632. https://doi.org/10.2134/jeq2019.01.0027

Grohs, M., Marchesan, E., Roso, R., Formentini, T. C., \& Oliveira, M. L. de. (2012). Desempenho de cultivares de arroz com uso de reguladores de crescimento, em diferentes sistemas de cultivo. Pesquisa Agropecuaria Brasileira, 47(6), 776- 
783. 204X2012000600007

Jindo, K., Olivares, F. L., Malcher, D. J. da P., Sánchez-Monedero, M. A., Kempenaar, C., \& Canellas, L. P. (2020). From Lab to Field: Role of Humic Substances Under Open-Field and Greenhouse Conditions as Biostimulant and Biocontrol Agent. Frontiers in Plant Science (Vol. 11, p. 426). Frontiers Media S.A. https://doi.org/10.3389/fpls.2020.00426

Maguire, J. D. (1962). Speed of GerminationAid In Selection And Evaluation for Seedling Emergence And Vigor1. Crop Science, 2(2), 176.

https://doi.org/10.2135/cropsci1962.0011183X0 00200020033x

Mendonça, E. S., \& Matos, E. S. (2005). Matéria orgânica do solo: Métodos de análises Viçosa, MG, Universidade Federal de Viçosa. 107p.

Noroozisharaf, A., \& Kaviani, M. (2018). Effect of soil application of humic acid on nutrients uptake, essential oil and chemical compositions of garden thyme (Thymus vulgaris L.) under greenhouse conditions. Physiology and Molecular Biology of Plants, 24(3), 423-431. https://doi.org/10.1007/s12298-018-0510-y

Seck, P. A., Diagne, A., Mohanty, S., \& Wopereis, M. C. S. (2012). Crops that feed the world 7: Rice. Food Security, 4(1), 7-24. https://doi.org/10.1007/s12571-012-0168-1

Shah, Z. H., Rehman, H. M., Akhtar, T., Alsamadany, H., Hamooh, B. T., Mujtaba, T., Daur, I., Al Zahrani, Y., Alzahrani, H. A. S., Ali, S., Yang, S. H., \& Chung, G. (2018). Humic substances: Determining potential molecular regulatory processes in plants. Frontiers in $\begin{array}{llll}\text { Plant } & \text { Science, } & 9, & \end{array}$ https://doi.org/10.3389/fpls.2018.00263
Silva, L. De S. Da, Silva, H. F. O. Da, Lima, A. C. B. De P., Tavares, O. C. H., García, A. C., \& Berbara, R. L. L. (2020). Efeito de Substâncias Húmicas em parâmetros morfológicos e na concentração de pigmentos cloroplastídicos da parte aérea de Oryza sativa L cv. Esmeralda. Cadernos de Agroecologia, 15(2), 1-4.

South, P. F., Cavanagh, A. P., Liu, H. W., \& Ort, D. R. (2019). Synthetic glycolate metabolism pathways stimulate crop growth and productivity in the field. Science, 363(6422). https://doi.org/10.1126/science.aat9077

Taiz, L., Zeiger, E., Møller, I. M., \& Murphy, A. (2017). Fisiologia e Desenvolvimento Vegetal 6. ed. Porto Alegre: Artmed. 858 p.

Team, R. C. (2020). R: A language and environment for statistical computing (4.0). $R$ Foundation for Statistical Computing; CRAN. http://www.r-project.org

USDA. (2020). Livestock and Poultry: World Markets and Trade COVID-19 Upends Global Protein Markets. Office of Global Analysis. Retrieved February 6, 2021, https://apps.fas.usda.gov/psdonline/circulars/liv estock_poultry.pdf

Yakhin, O. I., Lubyanov, A. A., Yakhin, I. A., \& Brown, P. H. (2017). Biostimulants in plant science: A global perspective. Frontiers in Plant Science, 7. https://doi.org/10.3389/fpls.2016.02049

Zhang, S., Li, Q., Ma, K., \& Chen, L. (2001). Temperature-dependent gas exchange and stomatal/non-stomatal limitation to $\mathrm{CO} 2$ assimilation of Quercus liaotungensis under midday high irradiance. Photosynthetica, 39(3), 383-388.

https://doi.org/10.1023/A:1015130326683 